\title{
A Concept: of Underpass Metro Elevated Structure in Mumbai Region
}

\author{
Malcom Baretto ${ }^{1}$, Raj Mhatre ${ }^{2}$, Virendra $\operatorname{Yadav}^{3}$, Mr. Naveen Hanchinahal ${ }^{4}$ \\ 1,2,3, (UG Students), ${ }^{4}$ Associate Professor, Department of Civil Engineering, St John College of Engineering \& \\ Management, Palghar
}

DOI: 10.46335/IJIES.2020.5.6.6

\begin{abstract}
Mumbai, the financial capital of Maharashtra, has now emerged as an important industrial and commercial center. Due to rapid development in economic, industrial and commercial activities, there is an enormous increase in traffic which causes traffic congestion and pollution problems and also forest deforestation. An elevated metro construction passing through commercial structure will minimize the deforestation of land by using the area of metro structure and not also will attract attention by its design but because a metro passing through a commercial structure in the heart of the city. This paper proposes that an elevated metro construction through a commercial structure will be more beneficial in many cases rather than an elevated metro as in Delhi, and Bangalore and highlights various parameters of its onsite implementation.
\end{abstract}

Keywords: - Metro through structure

\section{I- INTRODUCTION}

$\mathbf{T}_{\text {he }}$ infrastructure projects are important for development of a nation and are also a mirror of any country's development. However, most of the infrastructure projects on account of their sheer size and nature (namely, type, site/location, urban settling, etc.) are invariably accompanied by significant environmental and social impacts during different phases (namely, pre-construction, construction and operational phase) of the project.

The nature of these impacts could be either positive or negative, depending upon their potential to favorably or adversely affect the surrounding environment and also the resident community. The Gate Tower Building, with its 16 floors dedicated to offices, an attic for machinery and two underground basements, does not attract attention by design or height, but because a highway through the building. In Osaka, where it was built has been nicknamed the "Beehive", referring to its appearance of "lively and bustling place."

The Gate Tower Building was built in Fukushimaku, Osaka, Japan. Although the area is mainly residential, has some office buildings and a shopping area, as well as factories and wholesale business. Since the reasons are located on the outside of the building, passing through these floors without stopping, stopping amounting 4 floors from the ground floor and then not up to the 8th floor surface not occupied by the motorway between the fifth and seventh floors, is used for machinery and stairs.

The building against noise and vibration. In 1995, during the Great Hanshin Earthquake, some sections of the highway were severely damaged, but the Gate Tower Building and the sector of the road that crosses were unaffected. Seesaws Sangyo Co. Ltd., which owns the building, was not the only part in this construction had to make some concessions to accommodate the exit ramp Umeda.

The Hanshin Expressway late 90s, skyscrapers have been built for both home and office, mainly due to its proximity to Umeda and business centers. The building has a dual core construction with a circular cross section.

The Umeda out, towards Ikeda in the system Hanshin Expressway, passing between the fifth and seventh floors of this building and. The road is the tenant of those plants. The elevators, which for practical Corporation, was required to isolate the building from 
noise and vibration, this demand was made in several ways.

On one hand, the ramp is freestanding and is designed as a weighing bridge rests on pillars. Interestingly, as the closest building pillars are complemented nicely with the faceted façade. Second, where the "dogleg" ramp curves have wrapped the sides of the building, about 12 meters on each side, with a "silencer" which thus dampens the sounds of vehicles.

\section{II- SCARCITY OF LAND IN MUMBAI}

Land is scare in India, even though the country has a land area of about 328 million hectares which is the seventh largest land area among the countries around the world.

India is burdened with a population of 1210 million as per the 2011 census, which grew from 345 million from 117 per q.km in 1951 to 368 sq.km in 2011.

The population to land ratio is what make land accounting a matter linked to human development concerns. As the pace of growth in non-farm employment avenues lagged behind the population growth, it forces upon more than half of the population $(58 \%)$ to make out their living from agriculture and allied activities.

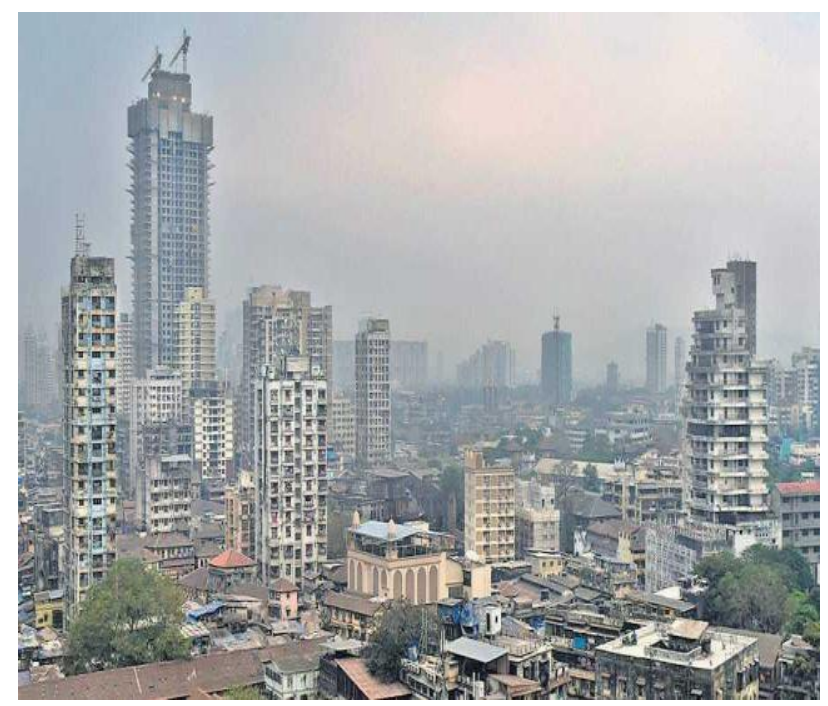

Figl - Scarcity of Land in Mumbai Metropolitan Area

Further, the demand for land other natural resources for non-farm use arising from urban spread and industrialization have not only shrunken the per capita availability of agricultural land in rural areas from 0.638 hectares in $1950 / 51$ to 0.27 hectares in $1988 / 99$ but strained its use, leaving devastating consequences on the quality and sustainable use of land. The direct and immediate impact of the deterioration in the quality of land is manifested on water availability and forest coverage, which has bearing on the vast section of the people who live in rural areas and use water as public and free good.

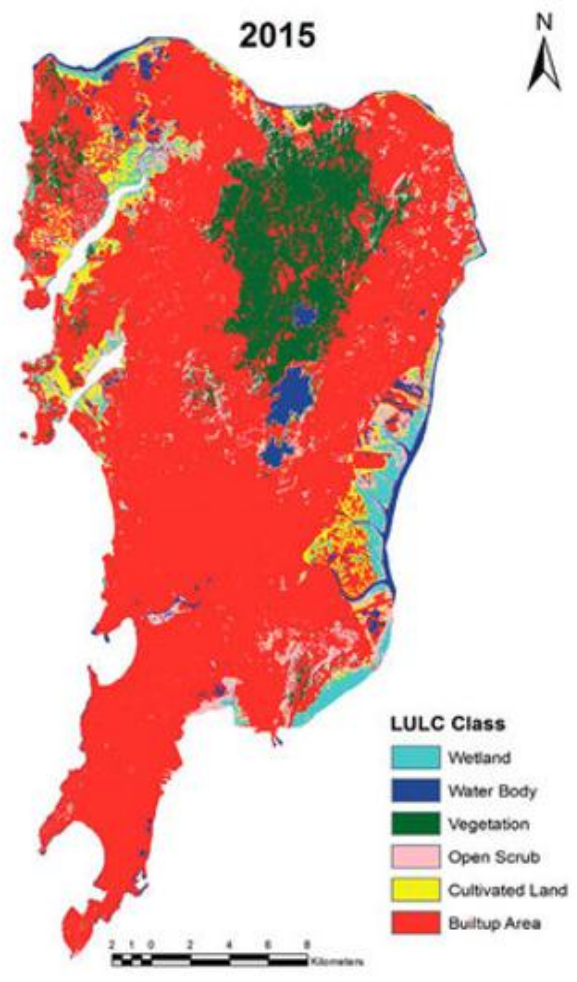

Fig 2 - Land Use pattern in Mumbai

It is important in India as $1 / 3^{\text {rd }}$ of the population live below the officially defined poverty norms. Moreover, the productivity fall driven decline in per capita availability of food, burdens that segment of the population, who suffer multifaceted deprivations such as lost entitlement to food due to state-supported encroachment of farm, forest cover coupled with inadequate purchasing market power.

\section{III- ELEVATED STRUCTURE}

Most of viaduct structures are being constructed using pre-cast segments installed using the underslung girder technique. The advantage of this technique is that it enables the viaduct deck spans to be erected very rapidly on site with minimal disruption to traffic below. Viaducts are essentially multi-spanned bridges crossing over roads or rivers or valleys.

On the Gautrain project, viaducts typically span in the order of 40 to $50 \mathrm{~m}$ between piers. Over the past months erection of viaduct decks has been ongoing at many locations along the route. Three girders are being used 
simultaneously and together they will erect approximately 10.5 kilometers of viaduct deck structure. Elevated metro has to run on the road at a height of about 10 meter. There will be a flyover like structure called via duct with pillars on road. Reduction in total road carriageway width by about 3 meters.

\section{IV- CONCEPTS OF GATE TOWER BUILDING}

- Type: - Office Building.

- Location: - 5-4-21 Fukushima, Fukushima-ku, Osaka.

- Country: - Japan

- Completed: - 1992

- Client: - Suezawa Sangyo Co. Ltd.

- Height: - $71.9 \mathrm{~m}(236 \mathrm{ft})$

A) Technical Details

- Structural System: - Reinforced Concrete and Partly steel frame.

- Floor count: - 16 above Ground, 2 underground, 1 Elevator Equipment tower Floor.

- Floor Area: - 7,956 m² (85,649 sq. Ft).

B) Design and Construction

- Architect: - Azusa Sekkei, YamamotoNishihara kenchiku Sekkei Jimusho

- Main Contractor: - Sato Kogyo Co. Ltd

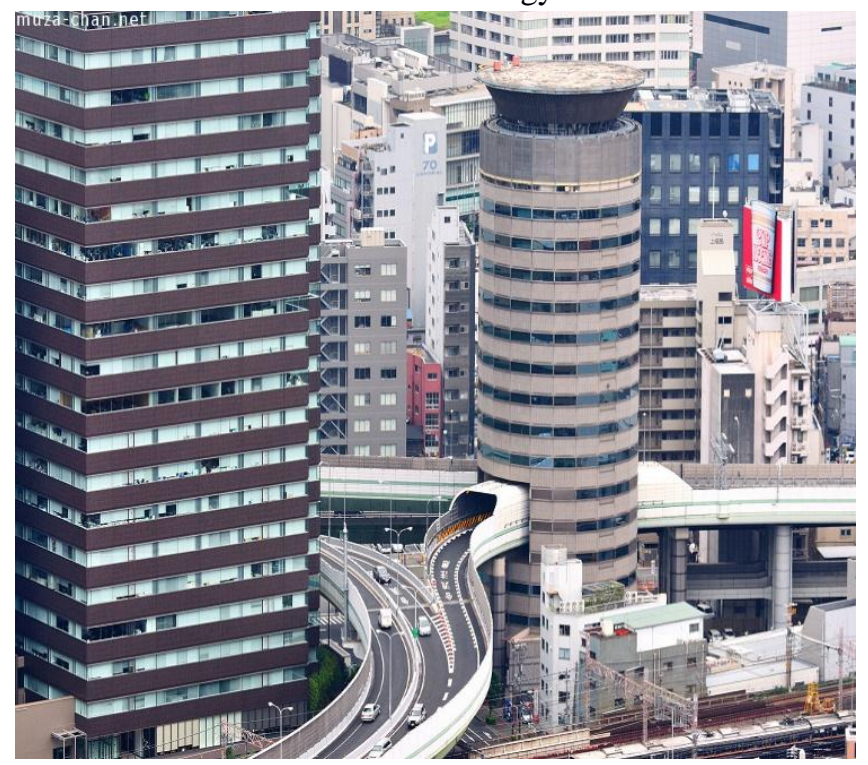

Fig 3 - Gate Tower Building in Japan (Source: wikipedia.org/wiki/Gate Tower Building)

\section{C) OVERVIEW}

The building has a double core construction, with a circular cross section. The Umeda Exit of the Ikeda Route of the Hanshin Expressway system (when exiting the highway from the direction of Ikeda) passes between the fifth through seventh floors of this building. The highway is the tenant of those floors. The elevator passes through the floors without stopping, floor 4 being followed by floor 8 . The floors through which the highway passes consist of elevators, number of apartments, stairways and machinery. The highway does not make contact with the building. It passes through as a bridge, held up by supports next to the building. The highway is surrounded by a structure to protect the building from noise and vibration. The roof has a helipad. In 1995, during the Great Hanshin Earthquake, some sections of the highway were severely damaged, but the Gate Tower Building and the sector of the road that crosses were unaffected

\section{D) SALIENT FEATURES OF THIS BUILDING: -}

1) USE OF VALUABLE LAND: The land used for construction of bridges and roads were further not be used for any other work but by applying us type of concept they can be used and the valuable land can be saved buildings can be made on the above of the land and parking area can be created below the road.

2) PROVISIONOF PARKING: In this concept the area can get a parking area for use. Parking area can be created of the side of the bridges by giving them external support. The area gets a parking which can be used by the common residency and also by the employees working in the commercial area.

3) EMPLOYMENT: Construction of junction building will give employment to many semiskilled and un-skilled labours. After construction, the building will be given to commercial centres like call centres, post office and etc. junction building can also be provided with banquet halls for functions and meetings.

4) INNOVATIVE: We define a new technology so that the structure can be used for two purpose without disturbing the existing structure. We are utilizing the area which covered by metro line passage by constructing the structure over the metro pathway. As construction is unique and has a pleasant appearance for tourist attraction in Mumbai Metropolitan Region. 


\section{V- SELECTION OF SUITABLE AREA FOR THIS TYPE OF CONSTRUCTION}

(Source: mmrda.maharashtra.gov.in/planning/metro line-1)

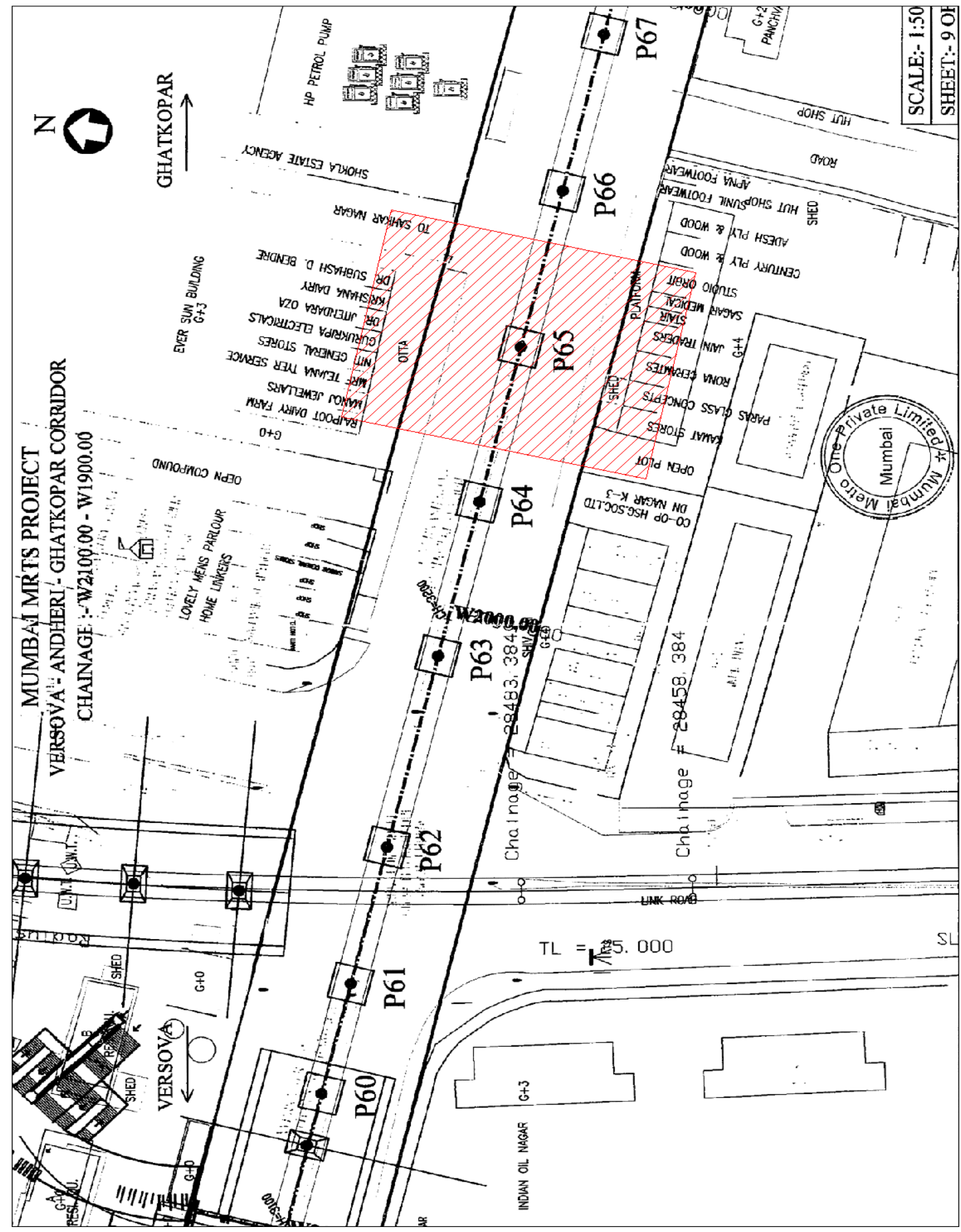

Fig 4- Versova-Andheri-Ghatkopar Metro line 


\subsection{REASON FOR SELECTION OF AREA AROUND AZAD NAGAR METRO STATION:}

A) Area between D N Nagar and Azad Nagar Station is now undergoing massive change because of redevelopment of old building and construction of new buildings.

B) Major transformation is seen in Residential, Commercial, Socio Economic, traffic and Property rates around this station area.

C) Proposed Metro Line 2 i.e. Charkop-Bandramankhurd is passing through this area, this Metro line is further planned to connect to Metro Line 3 and 4.

D) Due to its future connectivity with all parts of the city after implementation of metro Network this area has tremendous potential of attracting various businesses and eventually becomes Secondary Business District.

E) Local shops and small buildings are occupied between the area of this two-metro station in horizontal alignments by the construction of this type of building, the local shops and buildings are replaced in vertical alignments saving the valuable land in Mumbai Region.

F) The number of floors can be decided by the number of shops present around the proposed construction site. The elevated structure does include parking for vehicles at ground floor which eventually minimize the traffic congestion around the proposed site. The reason why the area between the D N Nagar and Azad Nagar metro station is decided for this type of construction because the concepts of Gate Tower Building in Japan is built on existing structures where the highway passing through the hollow section of the building therefor it is necessary to be include while planning for this type of structure.
5.2. 3D AUTOCAD DRAWING (360 view of structure: https://youtu.be/cTVVHBToMNc )

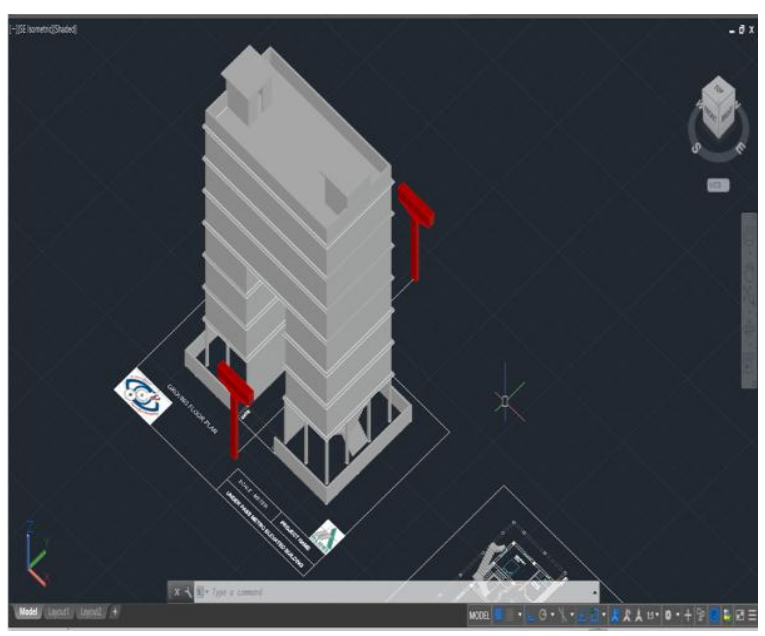

Fig No.5 (A) Top View of Structure

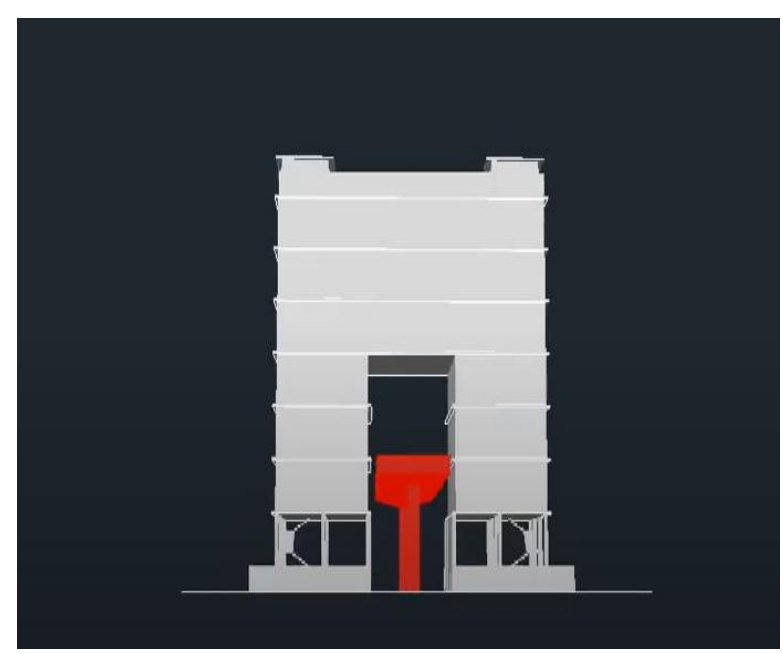

Fig No. 5 (B) Front View of Structure

VI- MUMBAI METRO GUIDELINES:

- Mumbai Metro line 1 which is from Versova to Ghatkopar in which the minimum site clearance area from column pier to the proposed construction of any structure or building is $4.5 \mathrm{~m}$ from both the sides. The way structure has been designed to be supported on single column erected along the medium of the road. At few places where it not possible to adopt the same portal frames supports have been adopted in lieu of single column.

- The depth of foundation proposed varies from 15 to 18 meters based on the geological data along the alignment. The width of the way structure has been 
proposed at 8.95 meters with track centres at 4.05 meters. The minimum clearance above road has been maintained at 5.5 meters location where alignment crosses railway tracks the minimum clearance has been kept at 6.55 meters as applicable for $25 \mathrm{kV}$ AC traction.

- A passage of $700 \mathrm{~mm}$ wide has been provided all along the corridor $6.5 \mathrm{~m}$ either side to facilitate evaluation of commuters during emergency. Ducts for laying electrical signals and communication cables have been provided. Provision has been made for drainage with connections to the underground drainage with a crossfall of $2.5 \%$ on deck top.

- The spans of the way structure have been mainly at 25 meters with minor adjustments at critical locations by use of shorter spans and adoption of 28,31- and 40-meters spans for road crossing and with 60 meters for crossing tracks. It is proposed to adopt 1.2-meter diameter piles for the major portion of structures up to 31 meters span and 1.5-meter diameter piles for 40-meter span and 2-meter diameter piles for 60-meter span.

- The total number of piles required for way structure for the entire alignment from Versova to Ghatkopar excluding depot and station buildings, including airport line to Sahara airport would be 3200 numbers It is expects that the piles would be 15 meters depth below the ground level and about 18-meter depth for 40 and above span.

Table 1: - Inter-Station Distances

\begin{tabular}{|l|l|c|}
\hline From & To & $\begin{array}{c}\text { Distances in } \\
\text { KM }\end{array}$ \\
\hline Versova & D N Nagar & 1.00 \\
\hline D N Nagar & Azad Nagar & 0.80 \\
\hline $\begin{array}{c}\text { Azad } \\
\text { Nagar }\end{array}$ & Andheri & 1.40 \\
\hline Andheri & $\begin{array}{c}\text { Western exp. } \\
\text { highway }\end{array}$ & 0.94 \\
\hline
\end{tabular}

- The piles will be anchored in to the hard rock about 1.5-2.0 meters as necessary. The entire way works would be divided into 2 sections to be executed by two independent agencies. Before commencement of excavation of the pile cap the area will be marked on the ground with reference to control points and centre -line pillars. The size of the piers for the majority of the spans between 25-31 meters would be 2-meter x 2.5 meters. For spans lower than 25 meters the size of the column would be $1.75 \times 2.5$ meters. The height of the piers from the top pf the pile cap to the bottom of the pier head is around 4-11 meters.

- The average height would be around 9 meters. The total quantity of concrete involved in piers would be approximately $25000 \mathrm{cu}$. Meters and steel would be 4000 metric tonnes.

- The scope of the project as stipulated in the bid documents in the bid documents covers the construction of a double line elevated standard gauge $(1435 \mathrm{~mm})$ rail corridor along VersovaAndheri-Ghatkopar involving 13 stations including a sour to international airport at Sahara. The total length of this corridor including the sour is 12.853 kms. the depot.

- The scope of the project as stipulated in the bid documents in the bid documents covers the construction of a double line elevated standard gauge $(1435 \mathrm{~mm})$ rail corridor along VersovaAndheri-Ghatkopar involving 13 stations including a sour to international airport at Sahara. The total length of this corridor including the sour is 12.853 kms. the depot.

\section{VII- FUTURE SCOPE OF THE PROJECT:}

- We define a new technology so that the structure can be used for two purpose without disturbing the existing structure.

- We are utilising the area which covered by metro line passage by constructing the structure over the metro pathway.

- In this, there is construction of partition wall to reduce vibration generated by metro rail.

- It provides a good structural view as well as aesthetic view.

- A hypothetical model or a program can be developed for design and analysis of composite column that can be run as an external program in the STAAD.Pro software.

- A further research for development of new technologies in composite construction can be easily workout.

- Recent development in composite construction technology, which have successfully transformed the market place in other countries, providing added value to the customers and rapid return on the invested capital. These, if adopted in India for residential and commercial building, could be very 
beneficial to the Indian community. In this regard, development of suitable design aids may be very fruitful.

- Design rules for composite construction have been developed gradually over the years and have been undergoing improvements and updating till today. These progressive changes resulted in more efficient uses of the constituent materials and led to better, less expensive structures. There is no doubt that the search for further improvements in this field will be certainly beneficial because it has very wide scope for further development.

- In this, there is construction of partition wall to reduce vibration generated by metro rail by providing vibration proof material to the surrounding structure.

- It provides a good structural view as well as aesthetic view.

\section{REFERENCES}

[1] Sharma N, Dhyani R, Gangopadhyay S. Critical Issues Related to Metro Rail Projects in India. Journal of Infrastructure Development [Internet]. 2013 [cited 1 May 2020];5(1):67-86. Available from: https://www.researchgate.net/publication/255710610 _Critical_Issues_Related_to_Metro_Rail_Projects_i n_India

[2] Gate Tower Building [Internet]. En.wikipedia.org. 2020 [cited 26 May 2020]. Available from: https://en.wikipedia.org/wiki/Gate_Tower_Building

[3] Liziba station [Internet]. En.wikipedia.org. 2020 [cited 1 May 2020]. Available from: https://en.wikipedia.org/wiki/Liziba_station

[4] Bhutani R, Ram S, Ravinder K. Impact of Metro Rail Construction Work Zone on Traffic Environment. Transportation Research Procedia [Internet]. 2016 [cited 1 May 2020];17:586-595. Available from: https://www.sciencedirect.com/science/article/pii/S2 352146516307281

[5] Kurzweil L. Prediction and control of noise from railway bridges and tracked transit elevated structures. Journal of Sound and Vibration. 1977;51(3):419-439.

[6] Li D, Cao G, Qiu H. Experimental Study of Environmental Noise from Metro Train. Advanced Materials Research. 2011;243-249:3440-3444.

[7] SIEMIATYCKI M. Message in a Metro: Building Urban Rail Infrastructure and Image in Delhi, India. International Journal of Urban and Regional Research. 2006;30(2):277-292.

[8] M. Ramachandran Metro Rail Projects in India: A Study in Project Planning

[9] Thakur M. Effect of Metro Rail on Land Use:(D.N. Nagar, Mumbai). International Journal for Research in Applied Science and Engineering Technology [Internet]. 2019;7(5):3794-3803. Available from: https://www.ijraset.com/fileserve.php?FID=23239

[10] Mumbai Metro [Internet]. En.wikipedia.org. 2020 [cited 26 May 2020]. Available from: https://en.wikipedia.org/wiki/Mumbai_Metro 